\title{
MEMORY AND SPACE IN KAZUO ISHIGURO'S NOVEL "THE BURIED GIANT": INTERMEDIAL ASPECT
}

\author{
Yaryna Oprisnyk \\ Postgraduate Student at the Department of World Literature, \\ Ivan Franko National University of Lviv, Ukraine \\ e-mail: yaryna.oprisnyk@lnu.edu.ua, orcid.org/0000-0003-4925-1364
}

\section{Summary}

The aim of the article is to investigate the phenomenon of intermediality in 2015 novel The Buried Giant by the British writer Kazuo Ishiguro. Particular attention is paid to the notion of "literary cinematographicness" (also known as cinematic or filmic mode), which is defined as the use of cinematic techniques and effects in literature, thus creating the effect of multimodality, with a dramatic-intensive flow of events in the text. Analyzing examples from Ishiguro's novel, the article focuses on such elements of literary cinematographicness as the prevalent audio-visual modality, with an in-depth semantics of sensory images and characters' non-verbal language; the abundance of audial and visual special effects; as well as incorporating different shots sizes, perspectives, and angles that produce the effect of multidimensional space in the recipient's mind. Furthermore, the novel's central motif of memory and recollections determines its non-linear chronotope, with such cinematic techniques as montage, dynamic frame shots, and flashbacks becoming instrumental in depicting the complex spatio-temporal relations between the scattered scenes and images.

Keywords: intermediality, literary cinematographicness, audio-visuality, shot, frame, montage, flashbacks, Kazuo Ishiguro.

\section{DOI: https://doi.org/10.23856/4807}

\section{Introduction}

Contemporary literature demonstrates a growing tendency of actively borrowing artistic effects and strategies of other art forms, a phenomenon known as intermediality, which is based on Marshall McLuhan's concept of the interaction of different "media", i.e., different channels of human communication. Swedish researcher Sara T. Linkis (Linkis, 2019) asserts that writers are increasingly using intermedial strategies to emphasize visual and material aspects of literature; accordingly, the concept of intermedial literature implies the meeting, confrontation, or convergence of literature - or traditional literary media - with other types of media. The intermediality of literature essentially implies its multimodality, that is, an attempt to convey information that is typically transmitted by other media, such as images, sounds, and spacio-temporal dynamics of certain phenomena. "Texts are always multimodal in the broadest, semiotic meaning of the term", as Marco Bellardi claims; thereby, he defines modes as "modalities whereby their mediality comes to be expressed and experienced: the material modality, the sensorial modality, the spatiotemporal modality and the semiotic modality", which are the cornerstones of all media and can be either material or mental (Bellardi, 2018: 38).

To a large extent, the foundations of the modern theory of intermediality were laid in the works of Mikhail Bakhtin, who pointed out that human language encodes information about the world around us and the society in which it operates; that is, language carries the 
collective experience of people, the whole "multitude of bounded verbal-ideological and social belief systems". Thereby, each word contains "various semantic and axiological content" (Bakhtin, 2010: 288) that indicates one's occupational sphere, features of a particular group, or worldview, which is actualized in a dialogue, i.e., any exchange of information or ideas between people. In this regard, various seemingly simple phenomena often have additional dimensions of abstract, socially, and culturally conditioned meanings, where "the dialectics of the object are interwoven with the social dialogue surrounding it" (Bakhtin, 2010: 278). Therefore, each word used in oral or written discourse (particularly in literature) appeals to the collective experience of people, this "common space" between the sender and the addressee, actualizing this dimension in the mind of the latter.

Probably, the most multifaceted example of intermediality in literature is literary cinematographicness (also termed as cinematic or filmic mode), whereby authors of fiction imitate the techniques and effects of cinema to dynamize the narrative, employing the reader's natural ability of visualizing the described sensory images with subsequent reconstruction of their invisible semantics. Since by its very nature cinema incorporates the elements of other forms of art (such as painting, sculpture, architecture, music, and theatre), one can argue that literary cinematographicness enables the maximal multimodality of the text. Most often, the cinematographicness of fiction presupposes the integration of cinematic aesthetics, terminology, plot-constructing techniques, and special artistic effects, which evoke in the reader a subconscious feeling of watching a film. In other words, literary cinematographicness is an example of intermedial transcoding, that is, according to Bakhtin (Bakhtin, 2010: 358), "the ability of language to represent another language", which in this case means the language of cinema as represented by means of a written word.

The works of the contemporary British writer of Japanese origin Kazuo Ishiguro are vivid examples of cinematic literature, whereby such principles of cinematographicness as audio-visuality, shots of different sizes, montage, and flexibility of the chronotope produce the effect of multidimensional and multisensory literary text.

The purpose of the article: to explore the techniques of literary cinematographicness in Kazuo Ishiguro's novel The Buried Giant.

\section{Tasks:}

1. To define the phenomenon of literary cinematographicness as an example of intermediality in the contemporary literature. narrative.

2. To investigate the cinematic artistic techniques that can be incorporated in a literary

3. To trace the system of cinematic effects and techniques in Kazuo Ishiguro's novel The Buried Giant.

Methodology: the purpose of the study led to the choice of the following methods and approaches: intermedial approach, dialogism, narratology, receptive aesthetics, hermeneutics, and close reading.

\section{The notion of literary cinematographicness and its constituents}

Due to the visual and montage-like nature of human thinking, and that of literature as a form of human thought, it can be argued that literary cinematographicness is to some extent inherent in all works of literature, even those written before the advent of cinema. Comparing the processes of reading books and watching movies, Marshall McLuhan (McLuhan, 1994: 144) 
claims they have much in common, noting that the task of the reader is to "follow the black and white sequences of stills that is typography, providing his own sound track. He tries to follow the contours of the author's mind, at varying speeds and with various illusions of understanding"; in view of this, the connection between the printed text and the film is indisputable and mainly lies in their unique ability to instigate the imagination of the reader or viewer

Nevertheless, more and more scholars (like G. Deleuze, H. M. Puchner, S. G. Kellman, F. Ivaldi, V. Fesenko, A. Pokulevska, N. Dotsenko, I. Martianova, T. Luk'yanets) differentiate the literary works with a visibly high level of "cinematographicness", where the authors seem to intentionally imitate the aesthetics and techniques of cinema, thus prompting the reader to unconsciously perceive these literary texts as if through the cinematographic lens. Particularly, as noted by Steven Kellman (Kellman, 1987: 473), one might consider cinematic a novel "organized as if separate chapters, paragraphs, or sentences were written and then edited into nonlinear patterns." In addition, cinematic prose aspires to imitate the visual presence of the film, in an attempt "to abandon concepts for percepts, telling for showing" (Kellman, 1987: 474). The reasons why writers resort to the techniques of cinematography can be different - from trying to make their work more dynamic and close to the modern reader, and to a conscious desire to convey the atmosphere of cinema. The appearance of cinematic techniques in a literary text can be explained by "the author's need to dynamize the observed image, to collide, to break its fragments in a paradoxical montage, their desire to control the perception of the reader-viewer" (Martianova, 2002: 9). Accordingly, literary cinematographicness is a feature of a text with the "mainly montage-like technique of composition, in which various, but above all compositional means depict a dynamic situation of observation" (Martianova, 2017: 138), hence significantly transforming the reader's receptive mechanisms, motivating the cinema-like multimodality of a literary text.

\subsection{Audio-visuality and special effects}

Among the major elements of literary cinematographicness one can distinguish the emphasized audio-visual nature of a literary text. Ukrainian scholar Valentyna Fesenko (Fesenko, 2014) notes that many contemporary novels demonstrate a pronounced photographic nature of the described visual images, their separateness and spontaneity. In such writings, one can observe a lack of emotional lexemes, thus imitating a "cinematic technique of a cold, impersonal view of the camera lens, which captures the phenomenological presence of things in the world" (Fesenko, 2014: 382). This means that a cinematic literary text is often purposefully devoid of the detailed descriptions of what cannot be directly seen or heard, with the inner world of the characters revealed not through descriptions of their thoughts and feelings, but indirectly, through actions, non-verbal language, dialogues, as well as the descriptions of environmental phenomena (such as images of nature and sounds) endowed with a culturally established symbolic and psychological meaning. Additionally, there are certain special audiovisual effects that further enhance the artistic, aesthetic, and emotional effect on the recipient. These include visual effects like blurring, playing with light and colors, contrast of light and darkness, blurry background, the effect of camera focus, as well as the sound effects like echo, contrast of silence and sound, background sounds, rhythm, and music (Bellardi, 2018). As a result, such arrangement of a literary narrative automatically reprograms the recipient onto the audio-visual code of perception, prompting them to not only visualize these images, but also independently reconstruct their metaphorical meaning as based on one's emotional intelligence and socio-cultural experience of the same. 


\subsection{Shots sizes and perspectives}

Another element of literary cinematographicness is the use of different shot sizes, angles, and perspectives. According to Yuriy Lotman (Lotman, 1973: 296), in a literary work, one can talk about the different shot sizes, "if successive segments of the text are filled with content that vividly contrasts in quantitative terms: different number of characters, whole and parts, descriptions of large and small objects; if one chapter in a novel describes the events of one day, and another - decades". Researcher Tetyana Luk'yanets (Luk'yanets, 2017a: 113) explains this technique in the cinema as "variation of the distance between the point of shooting and the object(s) in focus that is due to the phenomenon of analogy, or semantic and/or structural correlation depicted in successive frames". Accordingly, in a cinematographic writing, the world is arranged in visible shot sizes and perspectives, which manifest through such elements as detailed, metaphorically-imbued depictions of characters' appearance and non-verbal language (close-up and medium shots), their place of interaction (full and wide shots), the location of the action at the head of a scene (establishing shot), or descriptions of landscapes and distant objects (long shot) (Lannom, 2020). Furthermore, according to Luk'yanets (Luk'yanets, 2017b: 36), techniques of varying perspectives and angles (also termed as spatio-temporal focalization, verbal holographic modeling of artistic space, verbalization of geometric perspective of the image) "actualize the optical mode of perception through the reflection of shape, size, location of the object in the flow of a literary text, indicating the direction from which this object is observed by another character or an imaginary reader of the text", hence making the reader to reconstruct and visualize the whole system of spatial connections between the depicted objects just as described in a text.

\subsection{Montage and flexible chronotope}

In cinema, montage is a basic plot-constructing technique that makes the viewer perceive the separate frames as a holistic world, where the order of the combined fragments is dictated by a certain narrative and aesthetic idea. In literature, the term "montage" denotes such way of constructing a narrative that is dominated by the discontinuity of what is depicted in the text, namely, its fragmentary and elliptical nature. Moreover, as Fesenko (Fesenko, 2014: 387) appropriately notes, the use of montage technique in a literary work makes it more dynamic, helping to "fixate the spatial intensity of an image".

The montage in literature is closely intertwined with the chronotope flexibility, manifested through special narrative techniques of temporality construction - with elliptical transitions peculiar to cinema, sudden shifts of spatio-temporal coordinates, vivid time distortions, flashbacks, accelerated or slow-motion pace, etc. Due to these techniques, the literary text becomes "deprived of a linear chronology, which is replaced by a dramatic-intensive order of organizing events in time, creating a psychologically-motivated visual reality" (Luk'yanets, 2017a: 112). According to Lotman (Lotman, 1973: 65), such "propensity (of cinema) for unevenness, deliberate compression and stretching, is a prerequisite for the emergence of artistic time", which "is felt by the viewer as artistic energy, tension and semantic saturation". Therefore, just like a film director, the author of a cinematic literary text deliberately edits and shuffles various scenes and timelines, speeds up or slows down the course of events so as to achieve the desired artistic effect and draw the reader's attention to what is most important at this point in a story (Lotman, 1973). 


\section{Literary cinematographicness in Ishiguro's novel The Buried Giant}

Kazuo Ishiguro's writings are exemplars of contemporary postmodern literature that is characterized by hybridity, particularly on multicultural, multi-genre, and intermedial levels. The multicultural aspect in Ishiguro's works is based on a combination of Western ideas and forms with Eastern aesthetics, aimed at contemplation and in-depth symbolism of sensory images. Simultaneously, this principle determines the literary cinematographicness of Ishiguro's works, where the audio-visual orientation and montage-like segmentation of the narrative produce the effect of presence that is inherent to cinema. Furthermore, the elliptical nature of the writer's prose is determined by his "gap" strategy, with the true story and feelings of the characters hidden behind the scattered scenes and images in the text, while the whole picture is revealed to the reader only in the end of each novel. In addition, a motif of human memory and recollections is recurrent in all Ishiguro's novels, "reflecting the subtle malleability of memory and identity, and the simmering tension between the two, featuring a cast of characters scanning their past for clues to their identity, loss and abandonment" (Anjum, 2017: n.p.); notably, this theme requires a flexible combination of different timelines, whereby the technique of flashbacks becomes instrumental, enabling the author to spontaneously penetrate into the characters' memories.

Ishiguro's seventh novel The Buried Giant (2015) is a vivid example of the writer's artistic method, which can be considered postmodern in many ways: rethinking the mythopoetic genres of a legend, fairy tale, and fantasy through the prism of the modern worldview, allegorism, the motif of individual and collective unconscious, intertextuality, lack of clear moral criteria, subtle psychologism, the interweaving of several timelines, the open ending, and the appearance of the author in the text. Ishiguro himself noted about the connection between The Buried Giant and his earlier works: "I find that my themes remain very similar, but I like to change the periods in which they are set, and the genre" (Whitmore, 2017). In this case, the writer experiments with the genre of historical fantasy, representing "artistic rethinking of history", whereby "memory as the author's artistic concept finds expression at all levels of the work and is considered in numerous projections, interconnected with each other, creating a system of varieties" (Mihejkina, 2020: 1).

The events in The Buried Giant take place in the semi-legendary Britain of King Arthur's times, where an elderly couple, Axl and Beatrice, embark on a journey to find their son. On their way, the characters are constantly accompanied by a strange mist, which does not disappear on these lands for many years. Later it is revealed that this mist is the breath of a dragon, which deprives people of almost all the memories of their past ("the past $<\ldots>$ had somehow faded into a mist as dense as that which hung over the marshes" (Ishiguro, 2015: 11). Accordingly, the ubiquitous image of mist in the novel is a symbolic veil that covers the past, which the characters strive to uncover in order to answer the unspoken question that unconsciously haunts them, hence revealing their true identity. Notably, the image of mist is one of the common motifs of Japanese art, symbolizing the vagueness, uncertainty, and the illusory nature of the visible world. In cinematic terminology, this is represented by special visual effects like blurring, fades, and black-and-white picture. Another example of a visual metaphor in the novel is an episode where the contrast between the two banks of the river, light and dark, symbolizes the approaching of the characters to self-awareness as opposed to oblivion: "though the opposite bank was often bathed in morning light, their side of the river remained shaded and cold" (Ishiguro, 2015: 121). What defines the novel's plot structure is the motif of quest in its three 
interrelated manifestations: "characters travel on the way to their goals, while certain features of semantically significant landscape awaken their recollection, returning chaotic memories that become clear only at the end of the journey" (Borowska-Szerszun, 2016: 32). This plot structure is largely motivated by the "gap" strategy, where the true story is implied through the scattered memories, dreams, dialogues, and images, while the whole picture is revealed to the reader only in the end of the novel, when the characters come to final self-awareness.

The literary cinematographicness of The Buried Giant is represented by a set of narrative techniques and artistic effects that direct the reader's perception onto the polysensory, multimodal plane, where the described images are transformed into the visual stream of the montage-arranged scenes (much like a motion picture or the "stream-of-consciousness" technique). The predominant audio-visual modality of the text is embodied in the novel through the detailed descriptions of landscapes, natural phenomena and objects, a variety of open and closed spaces, as well as the abundance of remarks depicting characters' appearance and non-verbal language, indirectly expressing their emotions and thoughts. Furthermore, the visual richness of the novel is marked by a constant play with different shots sizes, perspectives, angles, light effects, and colors, which serve as the primary expression of the metaphorical and psycho-emotional meaning. The examples of the mentioned visual strategies in the novel are as follows:

"There were instead miles of desolate, uncultivated land; here and there rough-hewn paths over craggy hills or bleak moorland" (Ishiguro, 2015: 9) - this opening description resembles a "bird's eye view" landscape, analogous to the establishing long shot that demonstrates the general setting of the novel to the reader.

"Beatrice appeared confused again. She looked into his face, then all around her, at the pleasant sunshine, their neighbours once more giving attention to their activities" (Ishiguro, 2015: 19) - this fragment, starting with a close-up focus on characters' facial expressions ('Beatrice appeared confused again', 'looked into his face'), shifts towards full and wide shots, imitating the movement of the camera lens that alternately focuses on different objects ('looked into his face, then all around her, at the pleasant sunshine, their neighbours'). "A row of standing stones on the far horizon, a turn of a stream, the particular rise and fall of a valley" (Ishiguro, 2015: 21) - in the given quote, the character's gaze, just like the moving camera lens, highlights the details and outlines of the horizon, which is typical for a long shot in cinema, thus creating the panorama effect;

"After an initial descent it climbed steadily, till they found themselves walking along a high ridge, moorland on either side of them. The wind was fierce, but if anything a welcome antidote to the noon sun. The ground everywhere was covered in heather and gorse, never more than knee high, and only occasionally did a tree come into view - some solitary, crone-like specimen, bowed by endless gales. Then a valley appeared to their right." (Ishiguro, 2015: 23) - this passage is a colorful example of the spatial plasticity in the novel, with a number of lexemes denoting natural phenomena ('wind', 'noon sun', 'ground...covered in heather and gorse'), sizes and shapes ('high ridge', 'never more than knee high', 'cronelike', 'bowed'), directions ('descent', 'climbed'), as well as objects' position and distance relative to each other ('moorland on either side of them', 'occasionally did a tree come into view', ' $a$ valley appeared to their right'). Consequently, such scrupulous detailing of spatial relations between objects automatically constructs a three-dimensional picture in the reader's imagination with a pronounced effect of presence.

"Axl was puzzled that a village which from a distance looked to be two orderly rings of houses could turn out to be such a chaotic labyrinth now they were walking through its narrow lanes" (Ishiguro, 2015: 32) - here, we might observe the effect of a long shot ('from a distance 
looked to be two orderly rings of houses') being replaced by a wide shot ('a chaotic labyrinth now...walking through its narrow lanes'), which demonstrates the immediate environment of the character.

"From their low vantage point, the boat loomed large, and Axl could see in fine detail the damaged, coarsened wood, and the underside of the gunwale, where a row of tiny icicles hung like candlewax" (Ishiguro, 2015: 123); "The goat was clearly visible from where they now sat. The two large rocks, leaning one towards the other like an old married couple, had been visible from some way down" (Ishiguro, 2015: 132) - these passages also exemplify the attention to spatial positioning of different objects, utilizing a wide variety of space-defining lexemes ("low vantage point', 'clearly visible from where they now sat', 'leaning one towards the other', 'visible from some way down') as well as close-up focus ('could see in fine detail the damaged, coarsened wood... a row of tiny icicles hung').

"There was a bonfire blazing at its centre, and all around it, illuminated by its light, a large crowd. There were Saxons of all ages, even tiny children in their parents'arms, and Axl's first thought was that they had stumbled upon a pagan ceremony» (Ishiguro, 2015: 33) - here, the effects of focus on a particular object ('a bonfire blazing at its centre') and playing with light effects ('a bonfire blazing', 'illuminated by its light') are evident, as well as a wide shot effect due to the relatively small scale of the described scene;

“...they were in some sort of mausoleum, surrounded by walls bearing traces of murals and Roman letters. Before them a pair of substantial pillars formed a gateway into a further chamber of comparable proportions, and falling across this threshold was an intense pool of moonlight" (Ishiguro, 2015: 93) - the given fragment is a sample of interior description, with peculiar detail with regards to perspective and spatial relations inside the building ('surrounded by walls', 'before them a pair of substantial pillars', 'chamber of comparable proportions');

"Yet as they went forward they found there was a feeble light, so that at times they could even make out each other's outline" (Ishiguro, 2015: 90) - this scene is characterized by the effects of near complete darkness ('a feeble light') and silhouettes ('each other's outline').

"The candle in his hand illuminated his face and upper torso with wobbling shadows, and he was breathing heavily" (Ishiguro, 2015: 90) - in this quote, the image of the torso and face of the character suggest the medium shot, with the additional effect of the contrast of light and shadows ('illuminated', 'with wobbling shadows);

"...the grey-haired man had started to raise his arm, his fingers almost in a pointing gesture, a reprimand all but escaping his lips" (Ishiguro, 2015: 76) - this fragment exemplifies the detailing of the character's appearance, gestures, and facial expressions, which is analogous to a close-up technique in a movie;

"The monastery buildings were now dark shapes against the setting sky. As they drew closer, the monk paused, moved his forefinger over his lips, then continued at a more cautious pace" (Ishiguro, 2015: 82) - in this case, we observe the effects of contrast and twilight, as well as the transition from the long shot ('dark shapes against the setting sky') to close-up ('moved his forefinger over his lips').

In addition, the space described in the novel is further enriched with a multitude of sounds that vary in their intensity and source, overlap and mix with one another, or contrast with silence, setting the audial background and emotional tone of the narrative. For instance:

"...the stars had all but gone, a glow was spreading on the horizon, and the first notes of birdsong were emerging from the dimness" (Ishiguro, 2015: 10) - in this fragment, the described landscape of dawn is supplemented with the background sounds of 'birdsong ... emerging from the dimness'; "He could hear noises outside, but unlike those that had woken them in the night, these were of people going about their business of an ordinary morning" 
(Ishiguro, 2015: 42) - here, the background noise is characterized as that of 'people going about their business of an ordinary morning', making the reader imagine such sounds as based on their own experience of the same;

"...the sounds, even now echoing across the monastery grounds, of Wistan chopping firewood" (Ishiguro, 2015:72) - this quote exemplifies the audial effect of a peculiar sound ("chopping firewood') that produces the effect of echo, spreading 'across the monastery grounds'.

"...amidst the pleasant birdsong, there had been some strange hissings and murmurs", (Ishiguro, 2015: 100) - in this case, we might observe different sources of sounds that mix with one another ('the pleasant birdsong', 'strange hissings and murmurs');

"The noise followed a pattern: an intense burst of rustling, as of a struggle, then silence. Then soon, more rustling" (Ishiguro, 2015: 102) - the given quote is an example of the contrast between sound and silence ("intense burst of rustling... silence... more rustling").

"It was hard to determine how distant or near it had been, but the sound was unmistakably the cry of a beast; it had resembled the howl of a wolf, though there had also been something of the deeper roar of a bear» (Ishiguro, 2015: 59) - this passage emphasizes the impossibility of determining the distance to the source of a sound that is similar to a howl of an animal;

"And when he began to address the crowd, his voice, though loud enough for all to hear, somehow gave the impression he was speaking in a low, intimate tone appropriate to solemn subject matter. $<\ldots>$ A tone of entreaty had entered his voice. It was almost as if he was making an accusation, and Axl could feel the mood of the crowd changing $<\ldots>$ there was confusion, even fear in the rumble of voices swelling around him» (Ishiguro, 2015: 40-41) - this fragment describes the intonation of the character's speech, while its content is not heard from the point where the protagonist stands; at the same time, the effect of the speech on the audience is notable ('the mood of the crowd changing'), as well as how the sounds surround the protagonist from all sides ('voices swelling around him').

"Edwin, back in the shadows, had started to sing; faintly at first so that Axl had thought the boy was simply soothing his nerves, but then his voice had become steadily more conspicuous. His song seemed to be a slow lullaby, and he was rendering it with his face to the wall, his body rocking gently" (Ishiguro, 2015: 94) - the given quote describes the manner in which the character sings, while also expressing his evident change of mood ('faintly at first... simply soothing his nerves', 'his voice had become steadily more conspicuous').

Another modality clearly expressed in the novel is that of dynamics and action, which further enhances the effect of cinematographicness. Foremost, among the vivid examples of this strategy are various battle scenes in the novel, as in the following case:

At first both men held their swords pointing downwards, so as not to exhaust their arms. From his vantage point, Axl could see their positions clearly: at most five strides apart, Wistan's body angled slightly to the left. $<\ldots>$ he was taken aback by the suddenness with which Gawain and Wistan met. It was as if they had responded to a signal: the space between them vanished $<\ldots>$ As they did so, they rotated a little, like dancers, and Axl could then see that their two blades, perhaps because of the huge impact of their coming together, had become melded as one. (Ishiguro, 2015: 155-156)

In the given fragment, we observe the scrupulous detail with regards to the spatial positions and movements, firstly indicating the 'vantage point' of the spectator, much like the positioning of the camera lens in a film. Furthermore, in the scene, subdivision into a range of successive frames is evident through different movements of both fighters ('held their swords pointing downwards', 'Wistan's body angled slightly to the left', 'Gawain and Wistan met', 
'they rotated a little') and alternating shot sizes, starting with full shot depicting both characters at full height, to close-up focusing on peculiar detail ('their two blades...had become melded as one'). The dynamics of movements ('the suddenness with which Gawain and Wistan met', 'they rotated a little'), the emphasis on distances and angles ('pointing downwards', 'at most five strides apart', 'the space between them vanished') are also notable in this passage, which in combination create the effect of a highly tense and dynamic scene in an action movie.

In The Buried Giant, Ishiguro also employs montage, which is the result of a sudden change in spatio-temporal coordinates in the adjacent fragments of text. In addition to the various chapters that begin with a new scene (mostly through the panoramic establishing shot), the text of the novel is often split into smaller, less visible fragments, such as the transition to a new scene over a relatively short period of time, thus speeding-up the course of events, as, for example, in the following passage:

But Beatrice had already turned and was climbing the path back to the thorn tree and the figure in the flapping cloak.

A little later, having completed his errand, Axl was returning to the fields, and at the risk of testing the patience of his colleagues, deviated from his route to go past the old thorn again. (Ishiguro, 2015:15)

In the given fragment, we observe a sudden shift from one scene, where Beatrice 'had already turned and was climbing the path back to the thorn tree' to another, which probably occurred a few hours later, with the phrase 'a little later' marking the beginning of a new scene, where Axl 'was returning to the fields' and 'deviated from his route to go past the old thorn again'. In this case, the spatial coordinates do not change since in both scenes, the characters are near a certain thorn tree, but the temporal coordinates are different.

Furthermore, the defining feature of Ishiguro's novel is the interweaving of different timelines - the main one, which describes the scenes from the journey of the protagonists, and fragmented flashback memories from their distant and recent past. For instance:

...ever since Arthur's name had first been mentioned - a nagging, uneasy feeling had been troubling Axl. Now at last, as he listened to Wistan and the old knight talk, a fragment of memory came to him. It was not much, but it nevertheless brought him relief to have something to hold and examine. He remembered standing inside a tent, a large one of the sort an army will erect near a battlefield. It was night, and there was a heavy candle flickering, and the wind outside making the tent's walls suck and billow. There were others in the tent with him." (Ishiguro, 2015: 63)

In this fragment, certain associations of the protagonist ('ever since Arthur's name had first been mentioned') cause a spontaneous transition from the main timeline to the memory (' $a$ fragment of memory came to him'), followed by a description of the scene of the distant past ('he remembered standing inside a tent'). For the reader, this means an immediate and complete replacement of the "frame" in their inner movie, automatically redecorating the new mise-enscène with the necessary details and images that appear one by one as "instructed" by the text: ' a tent', 'a large one', 'a battlefield', 'night', 'a heavy candle flickering', 'the wind outside', 'others in the tent'.

Overall, the actual as well as symbolic journey of the characters through their memories leads them to a number of important discoveries about their past, including the fact that Beatrice has once betrayed Axl, and that as a revenge, albeit unconsciously, he did not allow her to visit the grave of their son, who had died of plague long time ago. In the end, restoring these memories enables the couple to comprehend their true feelings, hence finding ultimate understanding and peace. 


\section{Conclusions}

Kazuo Ishiguro's novel The Buried Giant is an example of contemporary postmodernist literature that utilizes intermedial strategies for a more profound interaction with the recipient's consciousness, primarily through the involvement of cinematic techniques and effects in the narrative.

In the novel, the predominant audio-visuality through the abundance of sensory images and special effects motivates the pronounced multimodality of the text, with a multitude of images and sounds becoming the primary expressions of nonverbalized psychological and symbolic meaning. Thereby, the artistic effect on the reader consists in the need to constantly visualize the described images and interpret their complex multilevel semantics as based on the person's emotional intelligence and socio-cultural experience of such phenomena. In addition, the novel incorporates the effects of different shots sizes (from long shot to close-up), perspectives, and angles, emphasizing the spatial connections between the depicted images, which prompts the reader to construct a multidimensional picture in their imagination, full of colors and sounds, creating the effect of immediate presence that is peculiar to cinema.

Moreover, the emphasis on the dynamics of events through the fragmented narrative, reminiscent of frames sequences and montage technique in cinema, further produces a film-like effect in the novel, allowing the writer to deliberately shift among different scenes and vary the pace of events. Last but not least, the essential feature of the narrative structure in The Buried Giant is the use of numerous spontaneous flashbacks into the memories of the characters, whereby the true idea of the novel resides. Consequently, such non-linear timeline requires the reader's ability to independently reconstruct all the spatio-temporal relations in the novel, forming a holistic story with both what is described in the text and what is untold, yet implied.

\section{References}

Anjum, N. (2017). Kazuo Ishiguro: A writer of the floating world. Retrieved from https:// thepunchmagazine.com/the-byword/non-fiction/kazuo-ishiguro-a-writer-of-the-floating-world Bakhtin, M. M. (2010). The dialogic imagination: Four essays (Vol. 1). Ostin, TE: University of Texas Press.

Bellardi, M. (2018). The cinematic mode in twentieth-century fiction a comparative approach (Doctoral dissertation). Birmingham: University of Birmingham.

Borowska-Szerszun, S. (2016). The giants beneath: Cultural memory and literature in Kazuo Ishiguro's The Buried Giant. CROSSROADS. A Journal of English Studies, 04(15), 30-41.

Fesenko, V. I. (2014). Literatura i zhyvopys: Intermedial nyj dyskurs: Navch. posibnyk [Literature and painting: Intermediate discourse: A textbook]. Kyiv: Vyd. Centr KNLU. [in Ukrainian]. Ishiguro, K. (2015). The buried giant. New York, NY: Alfred A. Knopf.

Kellman, S. G. (1987). The cinematic novel: Tracking a concept. Modern Fiction Studies, 33(3), 467-477.

Lannom, S.C. (2020). Guide to camera shots: Every shot size explained. Retrieved from https://www.studiobinder.com/blog/types-of-camera-shots-sizes-in-film/\#tve-jump-16d4d185912. Linkis, S. T. (2019). Memory, intermediality, and literature: Something to hold on to. London: Routledge.

Lotman, Y. M. (1973). Semiotika kino i problemy kinoestetiki [Semiotics of the film and the problem of cinema esthetics]. Tallinn: Eesti Raamat. [in Russian].

Luk'yanets, T. (2017a). Elementy kinopoetyky v hudozhn'omu teksti: Dosvid adaptaciyi 
kinematografichnyh pryjomiv $v$ anglomovnij hudozhnij prozi XX-XXI stolit' [The elements of cinema poetics in fiction: The experience of adapting cinematographic techniques in English prose of the XX-XXI centuries]. Naukovi Zapy sky', 153, 111-114. [in Ukrainian].

Luk'yanets, T. (2017b). Kinopryjomy'i kinotehniky v hudozhn'omu teksti: Semiotychne pidgruntya verbalnoyi transformaciyi [Cinematic techniques in a literary text: Semiotic basis of verbal transformation]. Visnyk Mariupol's kogo Derzhavnogo Gumanitarnogo Universytetu. Ser.: Filologiya, (17), 34-38. [in Ukrainian].

Martianova, I. A. (2002). Kinovek russkogo teksta: Paradoks literaturnoj kinematografichnosti [Cinema age of the Russian text: The paradox of literary cinematographicness]. Saint Petersburg: Saga. [in Russian].

Martianova, I. A. (2017). Kinematografichnost' sovremennogo teksta na materiale russkoj prozy [Cinematografy of literary text (on the material of the contemporary Russian prose]. Vestnik Chelyabinskogo Gosudarstvennogo Pedagogicheskogo Universiteta, 1, 136-141. [in Russian]. McLuhan, M. (1994). Understanding media: The extensions of man. Cambridge, MA: MIT Press.

Mihejkina, A. A. (2020). Koncept pamyati v romane Kazuo Ishiguro "Pogrebennyj Velikan" [The concept of memory in Kazuo Ishiguro's novel "The Burried Giant”]. Uchenye Zapiski Novgorodskogo Gosudarstvennogo Universiteta, 4(29), 1-5. [in Russian].

Whitmore, H. (2017) Nobel Laureate Kazuo Ishiguro: The Kingdom of Memory. Retrieved from https://www.barnesandnoble.com/review/kazuo-ishiguro-the-kingdom-of-memory 